\title{
How can meditation be salutary in dealing with alcohol use disorder?
}

\author{
Fung Kei Cheng* \\ Hong Kong, China
}

\begin{abstract}
Alcohol use disorder not only endangers individual physical and mental health, but also threatens social costs. Among multifarious treatments, meditation has become a growing option, with encouraging signs. This literature review provides an overview of the effectiveness of this approach, including mindfulness-based, vipassanā, and transcendental meditation, with 6,837 participants from the USA, the Netherlands, Italy, and Australia, in 27 research projects. Strengthening awareness and self-control, meditation practitioners were able to lessen drinking motives and disengage alcohol cues, resulting in alcohol-related self-efficacy, stress reduction, and finally dissipation of excessive alcohol consumption. These support the extension of using meditation in drinking interventions. In addition, recommendations are given for developing this method to tackle problematic alcohol use with more reliable data.
\end{abstract}

\section{Introduction}

Alcohol abuse remains a serious detriment to all age groups, from adolescents [1-3] to the elderly [4], engendering physical, mental, behavioural, financial, family, and social problems within individuals and their communities. More than three million deaths each year worldwide [5] are attributed to effects of a high risk factor associated with over 200 physical and mental illnesses and disabilities, including cancerous organ diseases, diabetes, cardiovascular failure, strokes, dementia, and psychotic disorders [6]. Thus, it incurs quantifiable and intangible social financial burdens [7]. The former covers health care expenditures, lower productivity, law enforcement costs, preventive and education expenses, and welfare budgets [8]; the latter encompasses poor quality of life, and inimical family relationships, causing family violence [9]. Worse, foetal alcohol syndrome induced by maternal alcohol consumption $[10,11]$ potentially produces genetic alcoholism [12] that harms newborns for their entire lifetime.

In order to tackle alcoholism, manifold treatments are utilised, mainly with medications, behavioural modification or combined approaches, achieving positive consequences; for example, using disulfiram, naltrexone, or acamprosate, along with cognitive behavioural therapy [13]. Meditation, a non-intrusive practice that cultivates neuro-behavioural energy [14], has also been applied to substance abuse and relapse $[15,16]$ since the 1970s, for instance, transcendental meditation [17-20]; among which Buddhist forms are increasingly adopted, including vipassanā and mindfulness meditation [21-25]. For example, a recent study has reported the effectiveness of a mindfulness-based relapse prevention programme among 168 participants affected by alcohol or drug dependence [26], which was supported by other research projects [27-29].

This literature review offers an overview of the effects of applying meditation to alcohol abuse, by sourcing 27 major electronic databases, such as the British Nursing Index, ProQuest Medical Library, MEDLINE, PsycARTICLES, PsycINFO, and PsycTESTS. The inclusion criteria are four-fold: (1) using only meditation, (2) merely examining problematic alcohol consumption, (3) adopting empirical methods, and (4) publishing in peer-reviewed journals. The exclusion criteria include: (1) duplications, and (2) theoretical exploration, literature reviews, book reviews, and dissertations.

\section{Findings and discussion}

The 27 reviewed projects involved 6,837 participants from the USA, Italy, the Netherlands, and Australia, including 3,816 (55.8\%) adolescents or college students: nine of which (33.3\%) were experimental studies. Only three randomised controlled trials $(11.1 \%)$ were carried out, with 484 (7.1\%) participants; and 18 (0.3\%) participants took part in another single qualitative inquiry.

Although the literature search was open to all forms of meditation, the output listed Buddhist-oriented meditative modes, mainly concerning mindfulness $(n=24,88.9 \%)$, together with vipassanā $(n=1$, $3.7 \%)$ and transcendental $(\mathrm{n}=2,7.4 \%)$ meditation.

\section{Mindfulness-based meditation}

Originating from the noble eightfold path, a key Buddhist tenet, the two basic elements of mindfulness are memory [30] and awareness [31]. Memory focuses on remembering virtues to accomplish inner purification through deep observation related to body, feelings, mind, and phenomena, from which awareness arises of one's own dirty corporeality, suffering, impermanence, and ever-changing self. These can be attained through mindfulness training, particularly meditation, resulting in knowing intrinsic characteristics such as emotional responses and personal weaknesses (including greed, hatred, and

Correspondence to: Fung Kei Cheng, Hong Kong, China; E-mail: oasischeng@ yahoo.com

Key words: alcoholism, literature review, mindfulness, transcendental meditation, vipassanā meditation

Received: September 08, 2016; Accepted: September 15, 2016; Published: September 20, 2016 
ignorance). Therefore, mindfulness has been extensively adopted for physical [32] and mental health treatments in individual [33] and organisational settings [34], covering a wide age spectrum from children [35] to seniors [36]. Its effectiveness on substance abuse [37, 38] and substance-induced mental illnesses [39] attracts attention to itself in the health care field.

As attributes in research associated with addiction, the five dimensions of mindfulness interpreted by Western scholars [40-42] comprise observing (attention to internal and external environments), describing (word expression of inner experiences), acting with awareness (present moment activities), non-judging (non-evaluation to thoughts and feelings), and non-reactivity to inner experiences (free flow of thoughts and feelings).

Mindfulness meditation contributes to enhancements in these dimensions which, for example, link a negative correlation with drinking motives [43] and alcohol-related stress [44]. Thirteen participants took part in 2-hour daily sessions from Monday to Friday for eight weeks, and practised 30 minutes of mindfulness-oriented meditation everyday at home [45], showing not only improvements in temperament and character maturity but also risk reductions in developing personality disorders and relapsing alcoholism.

Also, mindfulness training, guided by a 10-minute tape recording, was provided to 207 college students with problematic drinking to investigate the relationship between drinking motives, drinking behaviour, and mindfulness [46]. The outcomes presented an adverse correlation between acting with awareness and likelihood of harmful alcohol consumption, due to a lower level of drinking as a coping motive to reduce negative emotions. This association also applied to the factor non-judging. Moreover, greater acting with awareness is connected with weaker likelihood of alcohol overuse as a conformity motive to alleviate pressure from others. These were approved by Reynolds, Keough and O'Connor [47] from their survey among 76 informants. Another survey conducted with 316 participants added an inverse relationship between describing and alcohol consumption [48].

Despite the effects of mindfulness on overcoming alcohol misuse as presented earlier, Murphy and MacKillop [49] argued that these mindfulness traits were unable to predict impulsive alcohol consumption. An observation from another research indicated an insignificant relationship between observing and non-reactivity to inner experiences and alcoholism [48].

Mindfulness noticeably yields stronger positive implicit expectancy and weaker negative implicit expectancy [50] because it increases awareness and openness [51], and lessens attached thought [52]. Such strengths are conducive to better executive control [53] (higherorder regulation of thought and behaviour) and a decrease in thought suppression [54], thus regulating cue-reactivity and disengaging alcohol cues [55].

In addition to enhancements in self-control [56] and alleviation of stress reactivity and automatic compulsion as narrated by 18 young heavy alcohol users in a qualitative study after joining a 10week mindfulness-oriented recovery enhancement intervention [57], mindfulness weakens automatic alcohol motivation [58] but strengthens alcohol-related self-efficacy [59]. Consequently, it assists in less alcohol consumption and better mental health benefiting from a 8-week meditation course coupled with 30-minute daily home practice periods [60], including stress reduction [61], depression, anxiety, and alcohol-generated health problems due to gains in purpose in life [62].
Although a few projects were opposed to the effects of mindfulness on quantity, frequency, and duration of alcohol consumption [63], on reducing alcohol craving [64], on the mediating role between stressful life events and alcoholism [65], and on overall effects [66], these studies suffered from either small sample sizes or bare reliance on selfadministered survey questionnaires. However, these contrary outcomes may abate over-optimism towards the usefulness of meditation in alcoholism, and remind scholars of careful research design.

\section{Vipassanā meditation}

Vipassanā meditation emphasises insight into phenomenal reality, that is, the nature of the secular world, regarding transience, afflictions, and inconstant self, eventually aiming for emancipation. As reported by 173 participants who practised 8 to 10 hours of daily vipassanā meditation over a 10-day course, a non-randomised study indicated a significant decrease in unwanted thoughts about alcohol use [67]. This research presented favourable indicators; nevertheless, further confident data will be important for looking into the effects of this Buddhist meditative method on alcohol dependence.

\section{Transcendental meditation}

Popularised in the 1950s and developed from Buddhist ideas, transcendental meditation is a systematic, mantra-oriented deep breathing technique to cultivate inner happiness related to peace and balance [68]. A primary survey conducted with 1,862 instructors who practised transcendental meditation expressed that this practice could reduce hard liquor intake [69]. Additionally, Shaffii and the team [70] detailed the results of their project in that $40 \%$ of 216 participants who practised this meditation for two years discontinued alcohol use, and $60 \%$ did so within 25-39 months. In spite of these acceptable outcomes, recent academic research on this method has seemingly become inactive related to alcohol overuse.

\section{Limitations and future research directions}

Research methods and meditation modes can be discussed further to investigate their usefulness against alcohol use disorder. First, only one-third of the reviewed projects studied intervention programmes, while the remainder were based on telephone or Internet surveys. A rise in experimental research is desirable to enrich promising data on how meditation can deal with heavy alcohol consumption. Second, three randomised controlled trials did not yield sufficient scientific results. A randomised controlled research design is required to gather reliable data sets in an evidence-based manner, which minimises research biases. Third, the reviewed works used cross-sectional design without follow-up, which makes it difficult to determine their effectiveness in the long-term. Longitudinal studies are thus recommended to expand applications to alcohol-related problems. Fourth, in-depth interviews, either in individual or group context, can explore deeper understandings and thick descriptions of the lived experiences of people with alcohol use disorder. Hence, qualitative research is an advised method. Lastly, the diversification of meditative forms, for example Taoist meditation, is expected to extend choices for both health care professionals and people affected by alcoholism.

\section{Recommendations}

Common characteristics of addictive behaviour include emotional instability, stimulation, and loss of control [71], which can be improved by meditation, for instance, a reduction in craving alcohol [72]. The findings of this review support augmented applications of meditation 
to addiction therapies such as gambling [73], excessive social media use [74], and sexual addiction [75]. However, a qualified meditation instructor is essential to prevent illusion, delusion or hallucination when practising.

A general principle comes into play here: more frequent practice, more skilled techniques, and prolonged effectiveness. Therefore, meditation, as a coping strategy, is proposed to be practised regularly [76] and be integrated into daily life activities; for example, walking, eating, and cooking [77]. This feasibly exhibits favourable results for remedial and preventive purposes over the long-run.

\section{Conclusion}

Meditation is comparatively safe, economic, non-medicinal, and non-invasive. The positive signs from the 27 reviewed studies reveal the effects of meditation on alcohol use disorder pertaining to an extensive range of consequences from remedial and preventive perspectives, including lower drinking motivation, better alcohol disengagement, and greater alcohol-associated self-efficacy, resulting in a significant reduction in alcohol consumption. This practice also benefits alcoholincurred mental problems such as depression and anxiety. Although it is a potential measure for pathological alcohol dependence and relapse, further well-designed empirical research is necessary in order to collect substantial, reliable evidence.

\section{Source of funding support}

Preparation of this article did not receive any funding.

\section{Declaration of interest}

There is no conflict of interest to declare with respect to the present manuscript submitted for publication.

\section{References}

1. Patton R, Deluca P, Kaner E, Newbury-Birch D, Phillips T, et al. (2014) Alcohol screening and brief intervention for adolescents: the how, what and where of reducing alcohol consumption and related harm among young people. Alcohol Alcohol 49: 207212. [Crossref]

2. Chikere EIC, Mayowa MO (2011) Prevalence and perceived health effect of alcohol use among male undergraduate students in Owerri, South-East Nigeria: A descriptive cross-sectional study. BMC Public Health 11(1:18): 1-6.

3. Hanes M (2012) Effects and consequences of underage drinking. Juvenile Justice Bulletin September: 1-11.

4. Rogers J, Wiese B (2011) Geriatric drinkers: Evaluation and treatment for alcohol overuse. BC Medical Journal 53(7): 353-356.

5. World Health Organisation (2015) Alcohol.

6. Shield KD, Parry C, Rehm J (2013) Chronic diseases and conditions related to alcohol use. Alcohol Res 35: 155-173. [Crossref]

7. Single E, Collins D, Easton B, Harwood H, Lapsley H, et al. (2003) International guidelines for estimating the costs of substance abuse. 2nd ed. Geneva, Switzerland: World Health Organisation.

8. Burke TR1 (1988) The economic impact of alcohol abuse and alcoholism. Public Health Rep 103: 564-568. [Crossref]

9. Reinaldo AM, Pillon SC (2008) Alcohol effects on family relations: a case study. Rev Lat Am Enfermagem 16 Spec No: 529-534. [Crossref]

10. World Health Organisation (2004)Global status report on alcohol 2004. Geneva, Switzerland: World Health Organisation.

11. Sellers B (2005) Unique effects of alcoholism in women. Primary Psychiatry 12(1): 47-51.

12. Nieratschker V, Batra A, Fallgatter AJ1 (2013) Genetics and epigenetics of alcohol dependence. J Mol Psychiatry 1: 11. [Crossref]
13. Laaksonen E, Vuoristo-Myllys S, Koski-Jannes A, Alho H (2013) Combining medical treatment and CBT in treating alcohol-dependent patients: effects on life quality and general well-being. Alcohol Alcohol 48: 687-693. [Crossref]

14. Khanna S, Greeson JM (2013) A narrative review of yoga and mindfulness as complementary therapies for addiction. Complement Ther Med 21: 244-252. [Crossref]

15. Marlatt GA, Chawla N (2007) Meditation and alcohol use. South Med J 100: 451-453 [Crossref]

16. Dakwar E, Levin FR (2009) The emerging role of meditation in addressing psychiatric illness, with a focus on substance use disorders. Harv Rev Psychiatry 17: 254-267. [Crossref]

17. Orme-Johnson DW (1994) Transcendental meditation as an epidemiological approach drug and alcohol abuse: Theory, research, and Financial impact evaluation. Alcoholism Treatment Quarterly 11: 119-168.

18. Sharma HM, Dillbeck MC, Dillbeck SL (1994) Implementation of the transcendental meditation programme and Maharishi Ayur-Veda to prevent alcohol and drug abuse among juveniles at risk. Alcoholism Treatment Quarterly 11(3-4): 429-457.

19. Taub E, Steiner SS, Weingarten E, Walton KG (1994) Effectiveness of broad spectrum approaches to relapse prevention in severe alcoholism: A long-term, randomised, controlled trial of transcendental meditation, EMG biofeedback and electronic neurotherapy. Alcoholism Treatment Quarterly 11(1-2): 187-220.

20. Haaga DA, Grosswald S, Gaylord-King C, Rainforth M, Tanner M, et al. (2011) Effects of the Transcendental Meditation Program on Substance Use among University Students. Cardiol Res Pract 2011: 537101. [Crossref]

21. Witkiewitz K, Marlatt GA, Walker D (2005) Mindfulness-based relapse prevention for alcohol and substance use disorders. Journal of Cognitive Psychotherapy: An International Quarterly 19(3): 211-228.

22. Chiesa A, Serretti A (2014) Are mindfulness-based interventions effective for substance use disorders? A systematic review of the evidence. Subst Use Misuse 49: 492-512. [Crossref]

23. Zgierska A, Rabago D, Chawla N, Kushner K, Koehler R, et al. (2009) Mindfulness meditation for substance use disorders: a systematic review. Subst Abus 30: 266-294. [Crossref]

24. Simpson TL, Kaysen D, Bowen S, MacPherson LM, Chawla N, et al. (2007) PTSD symptoms, substance use, and vipassana meditation among incarcerated individuals. $J$ Trauma Stress 20: 239-249. [Crossref]

25. Marlatt GA, Witkiewitz K, Dillworth TM, Bowen SW, Parks GA, et al. (2011) in Mindfulness and acceptance: Expanding the cognitive-behavioural tradition. SC Hayes, VM Follette, MM Linehan. The Guilford Press: New York. pp 261-287.

26. Witkiewitz K, Bowen S (2010) Depression, craving, and substance use following a randomized trial of mindfulness-based relapse prevention. J Consult Clin Psychol 78 362-374. [Crossref]

27. Bowen S, Witkiewitz K, Clifasefi SL, Grow J, Chawla N, et al. (2014) Relative efficacy of mindfulness-based relapse prevention, standard relapse prevention, and treatment as usual for substance use disorders: a randomized clinical trial. JAMA Psychiatry 71 547-556. [Crossref]

28. Bowen S, Chawla N, Collins SE, Witkiewitz K, Hsu S, et al. (2009) Mindfulness-based relapse prevention for substance use disorders: a pilot efficacy trial. Subst Abus 30: 295-305. [Crossref]

29. Witkiewitz K, Warner K, Sully B, Barricks A, Stauffer C, et al. (2014) Randomised trial comparing mindfulness-based relapse prevention with relapse prevention for women offenders at a residential addiction treatment centre. Subst. Use Misuse 49: 536-546.

30. Bodhi B (2011) What does mindfulness really mean? A canonical perspective. Contemporary Buddhism 12: 19-39.

31. Brown KW, Ryan RM, Creswell JD (2007) Mindfulness: Theoretical foundations and evidence for its salutary effects. Psychological Inquiry: An International Journal for the Advancement of Psychological Theory 18: 211-237.

32. Murphy MJ, Mermelstein LC, Edwards KM, Gidycz CA (2012) The benefits of dispositional mindfulness in physical health: a longitudinal study of female college students. J Am Coll Health 60: 341-348. [Crossref]

33. Nestler S, Sierra M, Jay E-L, David AS (2015) Mindfulness and body awareness in depersonalisation disorder. Mindfulness 6: 1282-1285.

34. Cheng FK (2016) What does meditation contribute to workplace? An integrative review. Journal of Psychological Issues in Organisational Culture 6: 18-34. 
35. Cheng FK (2016) Is meditation conducive to mental well-being for adolescents? An integrative review for mental health nursing. International Journal of Africa Nursing Sciences 4: 7-19.

36. Keller BZ, Singh NN, Winton ASW (2014) Mindfulness-based cognitive approach for seniors (MBCAS): Programme development and implementation. Mindfulness 5: 453-459.

37. Wupperman P, Marlatt GA, Cunningham A, Bowen S, Berking M, et al. (2012) Mindfulness and modification therapy for behavioural dysregulation: Results from a pilot study targeting alcohol use and aggression in women. J. Clin. Psychol 68: 50-66.

38. Hsu SH, Collins SE, Marlatt GA (2013) Examining psychometric properties of distress tolerance and its moderation of mindfulness-based relapse prevention effects on alcohol and other drug use outcomes. Addict Behav 38: 1852-1858. [Crossref]

39. Smith BW, Ortiz JA, Steffen LE, Tooley EM, Wiggins KT, et al. (2011) Mindfulness is associated with fewer PTSD symptoms, depressive symptoms, physical symptoms, and alcohol problems in urban firefighters. J Consult Clin Psychol 79: 613-617. [Crossref]

40. Baer RA, Smith GT, Lykins E, Button D, Krietemeyer J, et al. (2008) Construct validity of the five facet mindfulness questionnaire in meditating and nonmeditating samples. Assessment 15: 329-342. [Crossref]

41. Baer RA, Smith GT, Hopkins J, Krietemeyer J, Toney L (2006) Using self-report assessment methods to explore facets of mindfulness. Assessment 13: 27-45. [Crossref]

42. Pepping CA, O'Donovan A, Davis PJ (2013) The positive effects of mindfulness on self-esteem. The Journal of Positive Psychology 8(5): 376-386.

43. Roos CR, Pearson MR, Brown DB (2015) Drinking motives mediate the negative associations between mindfulness facets and alcohol outcomes among college students. Psychology of Addictive Behaviours 29: 176-183.

44. Bodenlos JS, Noonan M, Wells SY (2013) Mindfulness and alcohol problems in college students: the mediating effects of stress. J Am Coll Health 61: 371-378. [Crossref]

45. Crescentini C, Matiz A, Fabbro F (2015) Improving personality/character traits in individuals with alcohol dependence: the influence of mindfulness-oriented meditation. J Addict Dis 34: 75-87. [Crossref]

46. Vinci C, Spears CA, Peltier MR, Copeland AL3 (2016) Drinking Motives Mediate the Relationship between Facets of Mindfulness and Problematic Alcohol Use. Mindfulness (N Y) 7: 754-763. [Crossref]

47. Reynolds A, Keough MT, O'Connor RM (2015) Is being mindful associated with reduced risk for internally-motivated drinking and alcohol use among undergraduates. Addictive Behaviours 42: 222-226.

48. Fernandez AC, Wood MD, Stein LAR, Rossi JS (2010) Measuring mindfulness and examining its relationship with alcohol use and negative consequences. Psychology of Addictive Behaviours 24: 608-616.

49. Murphy C, Mackillop J (2012) Living in the here and now: interrelationships between impulsivity, mindfulness, and alcohol misuse. Psychopharmacology (Berl) 219: 527 536. [Crossref]

50. McPherson A, Harris LM (2015) Mindfulness, explicit and implicit alcohol expectancies in alcohol dependent and non-alcohol dependent adults. International Journal of Mental Health and Addiction 13: 457-469.

51. Leigh J, Neighbors C (2009) Enhancement Motives Mediate the Positive Association Between Mind/Body Awareness and College Student Drinking. J Soc Clin Psychol 28 : 650-669. [Crossref]

52. Bramm SM, Cohn AM, Hagman BT (2013) Can Preoccupation with Alcohol Override the Protective Properties of Mindful Awareness on Problematic Drinking? Addict Disord Their Treat 12: 19-27. [Crossref]

53. Ostafin BD, Kassman KT, Wessel I (2013) Breaking the cycle of desire: Mindfulness and executive control weaken the relation between an implicit measure of alcohol valence and preoccupation with alcohol-related thoughts. Psychology of Addictive Behaviours 27: 1153-1158.

54. Garland EL, Gaylord SA, Boettiger CA, Howard MO (2010) Mindfulness training modifies cognitive, affective, and physiological mechanisms implied in alcohol dependence: Results of a randomised controlled pilot trial. J. Psychoactive Drugs 42: 177-192.

55. Garland EL1 (2011) Trait Mindfulness Predicts Attentional and Autonomic Regulation of Alcohol Cue-Reactivity. J Psychophysiol 25: 180-189. [Crossref]

56. Schellhas L, Ostafin BD, Palfai TP, de Jong PJ1 (2016) How to think about your drink: Action-identification and the relation between mindfulness and dyscontrolled drinking. Addict Behav 56: 51-56. [Crossref]
57. Garland EL, Schwarz NR, Kelly A, Whitt A, Howard MO (2012) Mindfulnessoriented recovery enhancement for alcohol dependence: Therapeutic mechanisms and intervention acceptability. Journal of Social Work Practice in the Addictions 12: 242-263.

58. Ostafin BD, Bauer C, Myxter P (2012) Mindfulness decouples the relation between automatic alcohol motivation and heavy drinking. J. Soc. Clin. Psychol. 31: 729-745.

59. Garland EL, Boettiger CA, Gaylord S, Chanon VW, Howard MO (2012) Mindfulness is Inversely Associated with Alcohol Attentional Bias Among Recovering AlcoholDependent Adults. Cognit Ther Res 36: 441-450. [Crossref]

60. Zgierska A, Rabago D, Zuelsdorff M, Coe C, Miller M, et al. (2008) Mindfulness meditation for alcohol relapse prevention: a feasibility pilot study. J Addict Med 2 165-173. [Crossref]

61. Adams CE, Cano MA, Heppner WL, Stewart DW, Correa-Fernández V, et al (2015) Testing a Moderated Mediation Model of Mindfulness, Psychosocial Stress, and Alcohol Use among African American Smokers.Mindfulness (N Y) 6: 315-325. [Crossref]

62. Pearson MR, Brown DB, Bravo AJ, Witkiewitz K (2015) Staying in the momen and finding purpose: The associations of trait mindfulness, decentering, and purpose in life with depressive symptoms, anxiety symptoms, and alcohol-related problems. Mindfulness 6: 645-653.

63. Karyadi KA, Cyders MA1 (2015) Elucidating the Association between Trai Mindfulness and Alcohol Use Behaviors among College Students. Mindfulness (N Y) 6: 1242-1249. [Crossref]

64. Murphy CM, MacKillop J (2014) Mindfulness as a strategy for coping with cue-elicited cravings for alcohol: an experimental examination. Alcohol Clin Exp Res 38: 1134 1142. [Crossref]

65. Christopher M, Ramsey M, Antick J (2013) The role of dispositional mindfulness in mitigating the impact of stress and impulsivity on alcohol-related problems. Addiction Research and Theory 21: 429-434.

66. Vernig PM, Orsillo SM (2009) Psychophysiological and self-reported emotional responding in alcohol-dependent college students: the impact of brief acceptance mindfulness instruction. Cogn Behav Ther 38: 174-183. [Crossref]

67. Bowen S, Witkiewitz K, Dillworth TM, Marlatt GA (2007) The role of thought suppression in the relationship between mindfulness meditation and alcohol use. Addict Behav 32: 2324-2328. [Crossref]

68. Bagheri H, Bagheri M (2013) Equilibration in transcendental meditation. Journal of Arts and Humanities 2: 14-20.

69. Benson H (1974) Decreased alcohol intake associated with the practice of meditation: a retrospective investigation. Ann N Y Acad Sci 233: 174-177. [Crossref]

70. Shafil M, Lavely R, Jaffe R (1975) Meditation and the prevention of alcohol abuse. $A m$ J Psychiatry 132: 942-945. [Crossref]

71. Deleuze J, Rochat L, Romo L, Van der Linden M, Achab S, et al. (2015) Prevalence and characteristics of addictive behaviours in a community sample: A latent class analysis. Addictive Behaviours Reports 1: 49-56.

72. Korlakunta A, Chary SRS, Reddy PKCM (2012) Reasons for relapse in patients with alcohol dependence. Andhra Pradesh Journal of Psychological Medicine 13: 108-204.

73. Chen P, Jindani F, Perry J, Turner NL (2014) Mindfulness and problem gambling treatment. Asian Journal of Gambling Issues and Public Health 4: 1-17.

74. Shonin E, Van Gordon W, Griffiths MD (2014) Mindfulness and the social media Journal of Mass Communication and Journalism 4: 1-4.

75. Van Gordon W, Shonin E, Griffiths MD1 (2016) Meditation Awareness Training for the Treatment of Sex Addiction: A Case Study. J Behav Addict 5: 363-372. [Crossref]

76. Kabat-Zinn J (2014) The challenge of a life's time-and a lifetime. Mindfulness 5: 334-340

77. Kabat-Zinn J (2005) Wherever you go there you are: Mindfulness meditation in everyday life. New York: Hyperion Books.

Copyright: (C2016 Cheng FK. This is an open-access article distributed under the terms of the Creative Commons Attribution License, which permits unrestricted use, distribution, and reproduction in any medium, provided the original author and source are credited. 